\title{
Looking at Organizational Socialization from the Developmental Network Perspective
}

\author{
Jihyun Chang', Taesung Kim²
}

Received: June 1, 2018 Revised: June 20, 2018 Accepted: July 30, 2018

\begin{abstract}
Paying close attention to those new to an organization, whether fresh or experienced, whose primary interest is in (re)socialization, the current study intends to (1) further the concept of mentoring from a bilateral relationship to a community and culture fostered by developmental networks, (2) propose an integrated conceptual framework for organizational socialization, and (3) suggest implications for practice and future research. This study reviews, analyzes, and integrates research assets and subsequently re-conceptualizes the aggregate information as valid propositions and a conceptual framework. The findings include (1) 11 propositions regarding the relationships among network characteristics (embeddedness, diversity), developmental functions (career support, psychosocial support, and role modeling), and socialization outcomes (learning and attitudinal outcomes); and (2) an integrated conceptual framework that depicts a comprehensive mechanism through which developmental networks conduce to organizational socialization of newcomers. Implications are that developmental networking must be an individual's fundamental competency and an essential part of organizational onboarding processes, and imperative for both members' career development and innovative organizational culture. By integrating research assets on the developmental phenomenon into conceptualizations, this study furthers the concept of mentoring to organizational culture and stimulates a substantive discourse for theory-building towards organizational socialization from the developmental network perspective.
\end{abstract}

Keywords: Organizational Socialization, Developmental Network, Mentoring, Career Development, Organizational Culture.

JEL Classification Code: D83, I29, M12.

\section{Introduction}

It is common today that a business comes in spot light only to quickly disappear, leaving no trace of its former presence. The same could be said for the occupational arena in which preexisting jobs and roles vanish and new ones emerge overnight (Frey \& Osborne, 2017; Schwab, 2017). Faced with this reality, individuals may pursue sustainable career development that potentially transcends organizational and conventional boundaries (Higgins \& Kram, 2001; McElroy \& Weng, 2016). At the same time, however, it still holds true that employees strive to take root

1 First Author, Ph.D., FMASSOCIATES BUSINESS ACADEMY, South Korea [Postal Address: 1414, 92 Saemunan-ro, Jongno-gu, Seoul, 03186, South Korea] E-mail: jchang0305@gmail.com

2 Corresponding Author, Ph.D., Department of Creative HRD, Institute of Social Sciences, Incheon National University, South Korea [Postal Address: 119 Academi-ro, Yeonsu-gu, Incheon, 22012, South Korea]

Tel: +82-32-835-8095, E-mail: tskim@inu.ac.kr in their current ground, more so for those who are at the early career stage or going through career change and job mobility (Litano \& Major, 2016; McElroy \& Weng, 2016). One way of achieving both ends is to cultivate relationships within and outside of the present job and organizationsocial connections that lead to opportunities for acquiring information, accessing resources, and securing support, among others (Hatala, 2006; Parker, Cotton, Yates, Baxter, \& Arend, 2017). In other words, today's workers require a variety of social interactions in order to achieve their goals in their current jobs, but also to attain continued success in their mid- to long-term careers (Higgins, Dobrow, \& Chandler, 2008).

Many studies have looked into social relations in the context of career development. Research has been particularly robust surrounding workplace mentoring - a oneto-one relationship between a mentor and a protégé in a hierarchical structure within the organization. Offering tremendous insights, the research stream has laid a foundation for further discussion that work- and careerrelated support is obtained not only from a solid line of connection with a mentor, but also through multiple sources 
such as an immediate boss, co-workers, seniors and colleagues in other departments, and acquaintances outside the organization (Dougherty, Ha Cheung, \& Florea, 2008). Gallo (2011) went further to call it a myth that people should find one perfect mentor and build a lasting formal relationship with the sage, and suggested instead to have a cadre of people to turn to for help and advice in various arrangements. Put differently, it seems plausible that career development takes place concurrently through a variety of ties with helpful individuals, namely a social network (Cotton, Shen, \& Livne-Tarandach, 2011; Parker et al., 2017). What remains, therefore, is the question of how such a network actually works.

Having social relationships is imperative particularly for those new to the organization, whether fresh or experienced as these individuals require support to build confidence in their person-organization fit, work performance, and professional identity (Blustein, Schultheiss, \& Flum, 2004; Greenhaus, Callanan, \& Godshalk, 2009). They learn about their expected roles and attitudes through interpersonal sources, as well as through formal channels (Chandler \& Kram, 2005; Greenhaus et al., 2009; Korte \& Lin, 2013; Kram, 1985; Morrison, 2002), and organizational socialization, a process by which incoming employees learn and adjust to their job and organization, would be unsuccessful without relational interactions (Allen, Eby, Chao, \& Bauer, 2017). This is why many companies institutionalize mentoring, coaching, on-the-job training (OJT), and other programs designed to facilitate learning and organizational adaptation for new joiners. It is, therefore, also reasonable that many mentoring and career-related network studies have paid attention to this population, as does this study.

There have been research attempts including the prominent one by Higgins and Kram (2001) that reconceptualized mentoring based on the notion of developmental network. The study presented a conceptual framework with the factors shaping a developmental network, a typology of such networks combined with their characteristics, and developmental consequences. The study also suggested that developmental support is a process linking the type of network to developmental consequences. However, neither this study nor any other has specified how an individual's network influences the content and amount of developmental support that eventually determines developmental consequences. In other words, the configuration of developmental network to affect organizational socialization has yet to be sufficiently investigated. Similarly limited is a comprehensive understanding of the mechanism in which a developmental network functions to promote desired developmental consequences. Although there have been studies in this vein (e.g., Chandler \& Kram, 2005; Dobrow \& Higgins, 2005), they failed to clearly distinguish a developmental phenomenon as a process and to specify the process by which the developmental consequences are produced.

A plausible assumption is that a developmental network itself may not cause developmental outcomes directly, but through the process of sharing, interacting, and sensemaking that functions in between (Baker \& Lattuca, 2010). That is, a developmental network enables such developmental functions to occur, and developmental outcomes may be the indirect result of the developmental network mediated by developmental functions. This reasoning comes from respective findings on the relationship between relational characteristics and developmental functions (Allen, Day, \& Lentz, 2005; Burke \& McKeen, 1997; Seibert, Kraimer, \& Liden, 2001; Wu, Foo, \& Turban, 2008), as well as on the relationship between developmental functions and developmental consequences (Kammeyer-Mueller \& Judge, 2008; Lankau \& Scandura, 2002). In a nutshell, as illustrated in Figure 1, developmental functions seem to act as a parameter between network characteristics (input variable) and developmental consequences (outcome variable), which calls for comprehensive examinations.

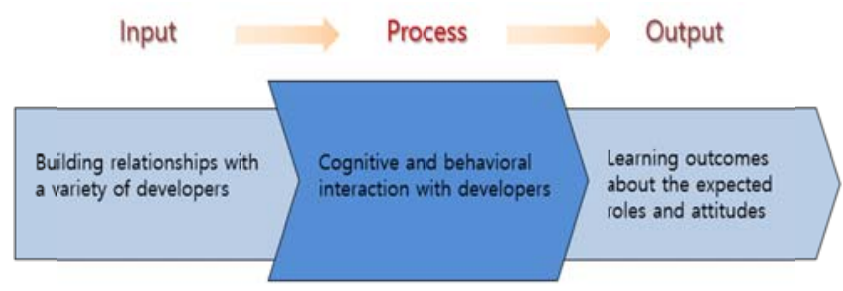

Figure 1. Process of learning and adaptation through social relations

Given this, the current study extensively investigates the research body on the developmental phenomenon for employees and attempts to integrate the findings into a comprehensive conceptual framework from the developmental network perspective. Paying close attention to new employees whose primary interest is in (re)socialization in their current organization, rather than an exploration of the external world, the framework depicts a mechanism through which developmental networks influence their learning and organizational adaptation. In essence, the purpose of this study is to (1) further the concept of mentoring from a one-to-one bilateral relationship to a community and culture fostered by developmental networks, (2) propose an integrated conceptual framework for organizational socialization, and (3) suggest implications for practice and future research. 
For a comprehensive, in-depth understanding of a phenomenon of focus, research assets must be reviewed, critically analyzed, and integrated (Chermack \& Passmore, 2005; Torraco, 2016); for theory building, this aggregate information should subsequently be re-conceptualized as valid propositions and a theoretical framework for the phenomenon (Callahan, 2010). Therefore, in achieving the research purpose, the current study employs an integrative literature review and a research-based conceptualization as its methodological approach.

\section{Putting Together the Pieces of the Developmental Phenomenon}

The critical components of the developmental phenomenon include the developmental network of a protégé, the network's developmental functions, and organizational socialization outcomes attained by the protégé.

\subsection{The Developmental Network}

Built on past mentoring approaches focused mainly on the bilateral relationship between mentor and protégé, recent ones have expanded the horizon by recognizing that people receive assistance in professional growth from social networks established in and outside of work. Arguing that career and psychosocial support is provided through a variety of channels, including traditionally defined mentorship, Higgins and Kram (2001) use the term "developer" to refer to any person who helps a protégé grow. They also define the "developmental network" as "the set of people a protégé names as taking an active interest in and action to advance the protégé's career by providing developmental assistance" (p.268). In other words, the developmental network is a type of social network that aids in the professional growth and career progression of a protégé.

As a social network, the developmental network is possessed of the characteristics of social capital that is inherent in relationships (Burt, 2005) and constructed with "embeddedness" and "diversity" (Adler \& Kwon, 2002).

Embeddedness is a characteristic of strong, intimate social relationships that are bound by confidence in norms and reciprocity and that represent the internal connections of a cohesive group (Coleman, 1987). Network embeddedness has been assessed by average tie strength and network density. Tie strength has been measured according to levels of intimacy, frequency of contact, or duration of relationships, with intimacy regarded as the best indicator as it is rarely distorted by other network measures (Marsden, 1990), and the average tie strength with egoconnected alters reflects the degree of embeddedness of a network (Higgins \& Kram, 2001; Morrison, 2002). Network density signifies how close the relationships within the network are. Network density refers to the ratio of actual connections to the focal individual to all possible connections within the network (Marsden, 1990) or to the degree of indirect connection between alters (Reagans \& McEvily, 2003). Since those in strong and dense relationships are inclined to help each other, a person in the relationship has a better chance to gain credible information, access high-quality resources, smoothly exchange and expand upon existing knowledge, collectively interpret context, and even seek psychological support when needed.

Diversity is another characteristic of social capital and is referred to as non-overlapping relationships with people in other groups (Burt, 2005; Granovetter, 1973). Diversity indicators include the size, range, and status composition of a network. Network size refers to the degree of expansion and is measured by the number of people connected to the focal individual - the number of connected alters in the egocentric network; and network range, on the other hand, is an indicator of mediation with the outside and is measured by the distribution of alters connected with diverse sources (Morrison, 2002; Oh, Chung, \& Labianca, 2004; Reagans \& McEvily, 2003). While network size refers only to the expansion of connections, network range signifies bridgebuilding with the outside, thereby allowing the protégé to acquire information and resources different from those within the affiliated group or organization (Lee, 2017). In the meantime, the status composition of a network is measured by the average status of alters within the network or the number of people at higher statuses than the focal individual (Lin, 1999; Morrison, 2002; Seibert, Kraimer, \& Liden, 2001). The status composition represents the hierarchical heterogeneity of a network and influences the quantity, quality, and diversity of assistance. Concerning the diversity of a network, therefore, it is imperative to take a simultaneous look at all these indicators because they are weakly correlated and register different aspects of diversity. That is, it is necessary to have a holistic overview of how all the components are configured in the developmental network.

A caveat is that, although embeddedness and diversity have been discussed as though contradicting, they are not mutually exclusive. Rather, they can co-exist interdependently, and optimal benefits can be obtained when the two are appropriately configured (Adler \& Kwon, 2002; Burt, 2005; Uzzi, 1999). 


\subsection{The Developmental Network and Developmental Functions}

Benefits from the developmental network include essential information, useful resources, psychosocial advocacy, and so forth. These benefits are the content of support offered by developers and serve as "developmental functions" for the protégé. To be more specific, developmental functions are categorized into career support psychosocial support, and role modeling (Scandura, 1992; Yang, Hu, Baranik, \& Lin, 2013; Parker et al., 2017). Career support involves offering sponsorship and coaching, facilitating exposure, and providing challenging tasks; psychosocial support includes advice, recommendations, and counseling regarding work and working life; and role modeling refers to the phenomenon in which the protége actively engages in the process of observing, imitating, or identifying with developers through cognitive and behavioral interactions. Given that the major source of these developmental functions is one's developmental network, whether and how the functions are secured is dependent on the configuration and degree of social capital accumulated in the network (Kammeyer-Mueller \& Judge, 2008; Scandura, 1992; Parker et al., 2017).

\subsubsection{Network embeddedness and developmental functions}

When embedded in a network - tied strongly and densely to many people within a network-one is more likely to acquire top-notch information and quality resources thanks to those ready to help in the network. The particular advantage of acquiring these from the embedded network is credibility and value based on mutual trust and care. Another advantage is in the interpretation of ambiguous, tacit, and politically complex knowledge that may be critical for properly responding to situations and deciding on appropriate behaviors.

There are many empirical studies in support of these notions. Allen et al. (2005) and Wu et al. (2008) found that tie strength in bilateral mentoring relations exerts a positive effect on both career and psychosocial support; Kim, Oh, and Kim (2006) and Chang and Chang (2009) reported that the average tie strength in a network positively influences career support, role modeling, and psychosocial support; Blickle, Witzki, and Schneider (2009) showed that developmental functions are positively influenced by individuals' degrees of effort in contacting multiple developers.

Thus, we present the following propositions:

$<\mathrm{P} 1 \mathrm{a}>$ : Network tie strength has a positive influence on developmental functions (career support, psychosocial support, and role modeling).

$<\mathrm{P} 1 \mathrm{~b}\rangle$ : Network density has a positive influence on developmental functions.

\subsubsection{Network diversity and developmental functions}

A social network characterized by diversity—network size, network range, and the status composition- connotes an openness to an influx of new ideas and different perspectives from many heterogeneous channels. An individual in such a developmental network has more exposure to what might be unfamiliar, different, and eyeopening (Burt, 2005; Lee, 2017) and thus, may be affected positively in many ways.

Regarding the relationship between network size and developmental functions, empirical findings are conflicting. Fagenson-Eland, Marks, and Amendola (1997) conducted a mentoring study, finding that protégés with many mentors receive higher-level career support; Blickle et al. (2009) agreed that protégés who maintain and use relationships with multiple developers enjoy an advantage. Recent studies caution that network size can have positive effects to some extent, but adverse effects may occur when investment in social capital goes excessive (Adler \& Kwon, 2002: Kim \& Chung, 2016). On the other hand, Kim et al. (2006) showed that network size does not affect career support in any way and even negatively affect psychosocial support; Chang and Chang (2009) also found that network size has no significant influence on career support, role modeling, or psychosocial support. In considering this contradiction, the latter findings deserve extra attention since the research subject in each of the cases was new employees. Different from their seasoned counterparts, these individuals experience high levels of uncertainty and anxiety and thus, actively seek out resources helpful for navigating their current organizations and job duties (Korte \& Lin, 2013; Saks, Uggerslev, \& Fassina, 2007). Since their keen interest is in specific, context-bound support rather than fragmentary data acquisition, these individuals find that having strong relationships with a few credible developers is more beneficial than having many superficial connections indifferent to their genuine needs.

As for the relationship between network range and developmental functions, empirical findings are mixed here too. Seibert et al. (2001) and Kim et al. (2006) reported that network range has a positive effect on information accessibility, career support, and psychosocial support for individuals at the mid-career phase or higher, whereas Chang and Chang (2009) found that network range exerts a negative influence on career support and role modeling and 
no influence on psychosocial support for early-career employees. It appears that these conflicting findings are related to the target population too. Seasoned incumbents who are already acclimated to their tasks and work environments would demand novel perspectives and different sources of inspiration. They seek to participate in creative activities and recover from the plateau of career development (Burlew, 1991; Greenhaus et al., 2009; Kram, 1985). Conversely, since the early stage of one's membership is marked by the intensive learning of and adaptation to tasks and working life in an organization, career support and role modeling from outside may confuse these individuals, resulting in adverse influence. In the meantime, it is noted that network range is likely to play negatively, regardless of career stage, for those in occupations or industries that require active knowledge exchange among internal groups (Lee, 2017).

Another disagreement found in mentoring studies is in regards to the effect of mentor status on developmental functions. Burke and McKeen (1997) reported the positive influence of a mentor's status on career planning, sponsorship, and psychosocial support, whereas Scandura and Viator (1994) found that a mentor's status had no influence on career support and role modeling and in fact a negative influence on psychosocial support. However, this disagreement seems to have been resolved in studies that adopt the network perspective. In these studies, the status factor has been found to exert a positive effect on information accessibility and career sponsorship (Seibert et al., 2001), as well as career support and role modeling (Chang \& Chang, 2009). Resources within a social relationship do not neutralize the value of that relationship, and the composition of a network differentiates the network from others (Lin, 1999). Status is also a social resource that distinguishes newcomers in the periphery from insiders close to the center. Therefore, when a protégé is in a developmental network filled with many such insiders, he/she is more likely to receive multi-dimensional substantive assistance (Baker \& Lattuca, 2010).

Thus, we present the following propositions:

$<\mathrm{P} 1 \mathrm{c}\rangle$ : Network size has no significant influence on developmental functions.

$<\mathrm{P} 1 \mathrm{~d}\rangle$ : Network range has a negative influence on developmental functions.

$<\mathrm{P} 1 \mathrm{e}>$ : The status composition of a network has a positive influence on developmental functions.

\subsection{The Developmental Network and Organizational Socialization}

A mentoring relationship is defined as a "relationship between a young adult and an older, more experienced adult that helps the younger individual learn to navigate the adult world and the world of work" (Kram, 1985, p.3). The aforementioned definition of developmental network also points to the network's role in providing developmental assistance to a protégé. Both definitions make clear that the mentor or developers provide help in order to encourage the socialization and growth of the protégé.

Put in context, socialization in the organization is "the process by which an individual acquires the social knowledge and skills necessary to assume an organizational role" (Van Maanen \& Schein, 1979, p.211). It embodies the learning of "those values, norms, and behavior patterns" that are necessary for any new member "as the price of membership" (Schein, 1968, p.3). In other words, organizational socialization is identified with mastering the knowledge necessary to fulfill job tasks and roles, fitting into the culture, and becoming integrated through interpersonal interactions (Chao, O'Leary-Kelly, Wolf, Klein, \& Gardner, 1994; Korte \& Lin, 2013).

In brief, establishing effective relationships with reliable informants and role models serves as a foundation for successful organizational socialization; the protégé's learning and attitude, major outcomes of organizational socialization, rely heavily on the configuration of his/her developmental network.

\subsubsection{Network embeddedness and organizational socialization}

Research and practice alike suggest that a protégé's relationship with his/her mentor or various developers positively contributes to the protégé's learning. One example is Korte and Lin (2013)'s qualitative study in which the relationships that new employees establish with managers and co-workers (i.e., formal and informal developers) were found to be an important determinant of the learning outcomes of their socialization.

Particularly in those embedded relationships marked by frequent contact or emotional intimacy, people have a strong motivation to help one another and co-create an atmosphere conducive to growing together. The learning content offered through these relationships is based on a sound understanding of the protégé's developmental needs, strengths, and weaknesses, and thus has greater depth and relevance. In addition, those in the network help the protégé move from legitimate peripheral participation toward full participation in workplace dynamics, thereby generating a sense of professional membership and motivation to properly operate in the given context (Lave \& Wenger, 1991). Research agrees that relationships based on trust and reciprocity contribute to the improvement of an individual's professional identity and competence (Higgins \& 
Kram, 2001) and that tie strength and the density of a network positively affect task achievement and role clarity (Morrison, 2002). Conversely, chances are that a protégé in a relationship with loose ties will neither learn effectively nor become committed to the membership as those in such a relationship care less about one another.

Thus, we present the following propositions:

$<$ 2a $>$ : Network tie strength has a positive influence on socialization outcomes.

$<\mathrm{P} 2 \mathrm{~b}\rangle$ : Network density has a positive influence on socialization outcomes.

\subsubsection{Network diversity and organizational socialization}

Diversity in a network is likely to increase an individual's access to a multitude of discrete resources and positively contribute to his/her learning of new knowledge, skills, or capabilities (Lee, 2017; Seibert et al., 2001). However, for new comers to the organization, mixed implications might exist in terms of diversity indicators-network size, network range, and network status composition.

A common sense is that those with large networks are likely to have more information and resources. While seemingly correct, however, such information and resources might also be simpler and more fragmented, thus making them ineffective in quenching the distinctive thirst of newcomers. Necessary for these particular individuals is contextual and interpretative guidance, as well as practical assistance in processing it. In other words, mere abundance of information does not necessarily satisfy the protégé's genuine needs, which suggests the lack of a correlation between network size and organizational socialization. In addition, since network size does not take into account whether relationships exist within or outside the organization, information and resources gained from such relationships may or may not be relevant to the protégé's organizational and work context.

Network range indicates a greater possibility of new knowledge and resources coming from outside the affiliated organization. A large network range signifies many external sources with whom the focal individual is in contact and from whom he/she can gain a broad range of information. However, given that the priority for new joiners is to fulfill their assigned tasks and become integrated into their organization, a network comprised of many externals is not necessarily more advantageous than one comprised mainly of internals. Assuming that average tie strength is the same in both networks, developers affiliated with the same organization provide content better tailored to the protégé's needs and, therefore, contribute more to his/her learning and organizational acclimation. Information from external relationships might even produce negative effects by causing ambiguity, mismatch, or confusion, as found in a study of accountants at a large firm in which network range increased role ambiguity (Morrison, 2002).

The status, as discussed, represents not only how high one is in the organizational hierarchy but also how close he/she is to the core of the organization. More often than not, the higher the developer is ranked, the closer he/she is to being an insider who has more experience in practical dealings and knows more about the expectations and politics of the given organization. Therefore, when connected with diverse walks of organization, the protégé is likely to learn better through opportunities such as coaching, guidance, or observation (Baker \& Lattuca, 2010). In fact, standards of organizational knowledge and task achievement were found to be higher when the average status of alters within the network was higher (Morrison, 2002). In addition, since learning occurs through informal exchanges and incidental encounters, as well as through formal interventions (Marsick \& Watkins, 2001), variegated network composition serves as a fertile condition for quality organizational socialization. Given that protégés are relatively new to the organization, varied developers in the network in terms of rank and tenure would allow them multidimensional and synergetic learning opportunities.

Thus, we present the following propositions:

$<P 2 c>$ : Network size has no significant influence on socialization outcomes.

$<$ P2d $>$ : Network range has a negative influence on socialization outcomes.

$<\mathrm{P} 2 \mathrm{e}\rangle$ : The status composition of a network has a positive influence on socialization outcomes.

\subsection{Developmental Functions in Between}

The process of participating in social interactions for sense-making and value-sharing takes place based on a human network (Baker \& Lattuca, 2010). This process corresponds with developmental functions that include the acquisition of information and the expansion of accessibility (career support), emotional support and encouragement (psychosocial support), and the search for and imitation of desirable behavior (role modeling). Combined, the developmental network itself might not have a direct effect on learning and attitudinal outcomes of socialization. Rather, the process works and functions to deliver the advantages of the developmental network to the protégé for his/her successful organizational socialization.

As noted, developmental functions are directly impacted by developmental network characteristics. Given that a configuration is a systematic environment that facilitates 
certain goal-serving functions to produce desired results, the outcomes of socialization (outcome variables) should be viewed as the indirect results of developmental network characteristics (input variables), as mediated by developmental functions (mediator variable). This conceptualization is supported by the studies that have confirmed the causal relationship between relational characteristics and developmental functions (Allen et al., 2005; Burke \& McKeen, 1997; Seibert et al., 2001; Wu et al., 2008), as well as between developmental functions and socialization outcomes (Kammeyer-Mueller \& Judge, 2008; Lankau \& Scandura, 2002). It is also supported by sociocultural learning theory that explains in detail how learning is generated through social interactions (Baker \& Lattuca, 2010). Proposed in the theory is a social and cognitive process by which a newcomer forms relations with insiders, which subsequently allow the employee to participate with gradually increasing frequency in activities related to his/her socio-cultural context. Through this increased social interaction, the employee eventually becomes a central insider and manifests epistemological (knowledge, learning) and ontological (identity, attitude) changes. Cognitive and behavioral interactions with others are viewed as a precondition for learning according to the organizational learning perspective as well (Crossan, Lane, \& White, 1999)

In sum, developmental functions, or social interactions in socio-cultural learning theory, have been identified as the mediator between developmental networks and organizational socialization outcomes, although the specific details of this structural relationship have not been empirically tested.

Thus, we present the following proposition:
<P3>: Developmental functions mediate the relationship between the developmental network and organizational socialization outcomes.

\section{Conceptualizing an Integrated Framework}

Based on the extensive review and interpretive synthesis of the literature on mentoring, developmental networks, and organizational socialization, the current study conceptualizes an integrated framework that shows how organizational socialization takes place for those new to the organization (see Figure 1).

Depicted within this framework are the components (developmental network characteristics, developmental functions, organizational socialization outcomes) and their relationships suggested as the propositions. In detail, developmental network characteristics directly influence developmental functions in multiple ways. Among network characteristics, tie strength and density-the indicators of embeddedness-have a positive effect on developmental functions (<P1a>, $<\mathrm{P} 1 \mathrm{~b}>)$, while diversity indicators demonstrate inconsistent results. In particular, network size does not exert an influence on developmental functions $(<\mathrm{P} 1 \mathrm{C}>)$; network range affects developmental functions negatively, $(<\mathrm{P} 1 \mathrm{~d}>)$; and status composition has a positive influence $(<\mathrm{P} 1 \mathrm{e}>)$. Developmental network characteristics directly influence organizational socialization outcomes as well, in which tie strength and density exert a positive effect $(<\mathrm{P} 2 \mathrm{a}\rangle,\langle\mathrm{P} 2 \mathrm{~b}\rangle)$ while diversity indicators again show mixed results $(<P 2 c\rangle,\langle P 2 d>,\langle P 2 e>)$. Combined is the structural mechanism in which developmental network characteristics exert an influence on organizational socialization outcomes with mediation by developmental functions in between $(<\mathrm{P} 3>)$.

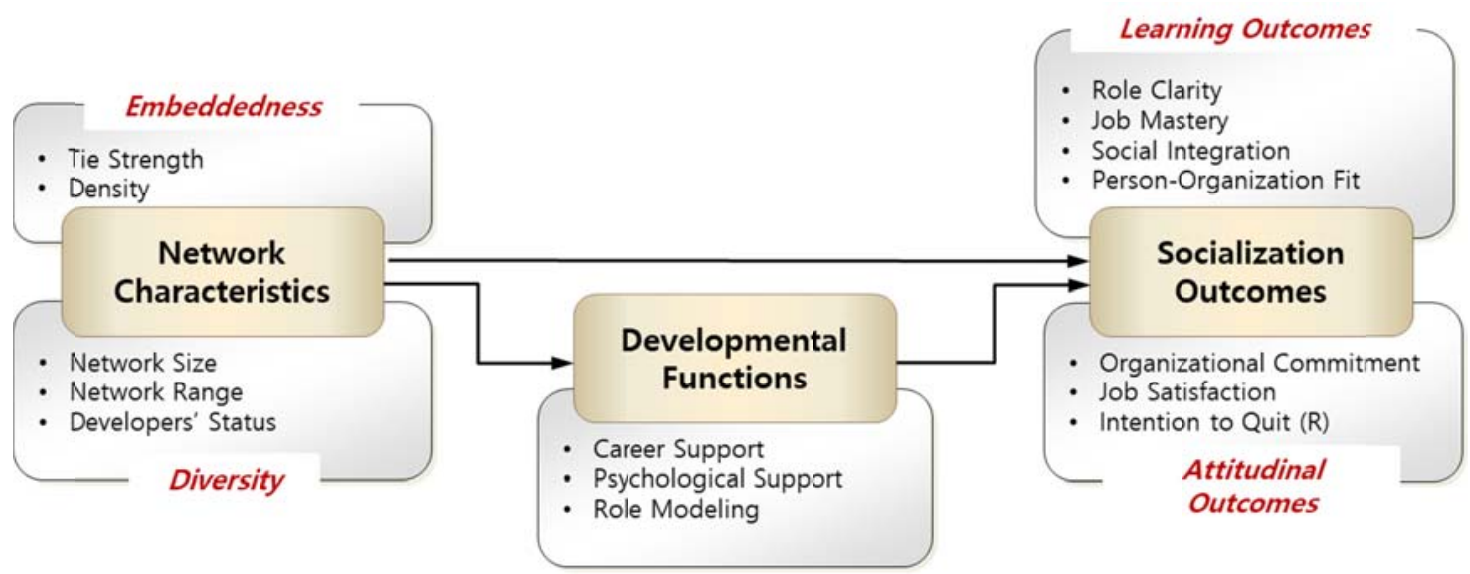

Figure 2. Conceptual framework for organizational socialization 
It should be reminded that the suggested framework concerns particularly those new to an organization, as relationships may take different patterns or include other developmental consequences depending on the phase of career progression (Burlew, 1991; Greenhaus et al., 2009; Kram, 1985).

\section{Discussion}

The conceptualizations thus far demonstrate how organizational socialization is facilitated by developmental networks formed by/for newcomers. Now, in order to stimulate a substantive discourse for theory-building towards organizational socialization from the developmental network perspective, as well as practical applications of the findings, this study suggests implications for practice and research.

\subsection{Implications for Practice}

New joiners learn and adapt in the workplace by forming networks with helpful people, called developers, who provide assistance for professional success and career development. These employees will learn more, perform better, and develop well when tapped into a network with the adequate strength and diversity of developmental relationships. In fact, the practice of interpersonal networking would become more important in today's business world that makes it more likely for workers to have increased opportunities for internal and external mobility, experience multiple career shifts over the course of professional lives, and continue with repeated (re)socialization and longer-term career growth (Blustein et al., 2004; Greenhaus et al., 2009; Litano \& Major, 2016; Lee Lim, \& Suh, 2014). What adds to this is the unprecedented technological advancement that affects the way people work and communicate. People are now able to obtain a tremendous amount of information through various intellectual sources and work completely apart from others while, at the same time, still being interdependent for solving problems, coping with challenges, and navigating workplace realities. All these combined suggest that the seamless mesh of in-person and virtual relationships be paramount for success of both individuals and the organization in the era of protean career and massive connectivity. Therefore, smart networking with developers must be a fundamental competency of employees and an essential part of onboarding processes set in place in the organization.

The developmental network's contribution goes beyond providing career-related assistance. It also serves as an ecology in which potential leaders are supported by more than just a few supervisors, are sometimes challenged with different perspectives, and ultimately become well-rounded, allowing them to deliver value to the organization, its customers, and wider society. Caplan (2013) points out that "command and control" styles of management have given way to a new leadership model that promotes "shared values, shared visions and shared understanding" (p. 20). This is acutely true in the contemporary workplace where lateral communications, synergetic collaborations, and responsible work ethics are honored than ever. Therefore, weaving the sophisticated web of developmental networks is not merely a technical maneuver, but also a strategic move for the sustainable success of individuals and organizations alike. An organization filled with a host of intertwined formal and informal developmental networks will have a better chance to foster a culture of collective intelligence, inclusion and balance, ethical pluralism, to name a few, and therefore prosper. The research-based propositions and framework proposed herein are intended to nudge organizational leaders into revisiting whether their organizational culture is top-down and uni-directional, like the conventional mentormentee relationship structure, or multi-directional and cooperative as an interconnected community.

Many agree that employees' development can be attributed to work experiences, learning from others, and formal training by $70 \%, 20 \%$, and $10 \%$, respectively (Lombardo \& Eichinger, 2000), although some criticize that the means of derivation for these percentages is unclear. Setting aside the technical debate, it can be suggested that developmental interactions such as learning from role models, constructive feedback, and mentoring and coaching in an actual work context outweigh formally designed training programs in terms of positive influence. Further to these advantages of developmental functions is creativity and innovation that come with divergence and convergence of many different perspectives. Described as messy and reiterative (Anderson, Potočnik, \& Zhou, 2014), the innovation process calls for a platform in which people connect together to generate, promote, and realize ideas (Janssen, 2005). These notions imply how well the developmental network could serve as the platform for exchange, experiments, and co-creation of collaborative innovations. Again, the importance and desirable returns of developmental networking are highlighted here, calling for organizational leaders to pay attention to the "asset value of human relationships" (Harrison \& Kessels, 2004, p.88) for both members' career development and innovative organizational culture.

\subsection{Implications for Research}

First of all, this study should serve as a basis for the development of empirically verifiable hypotheses and 
framework. A considerable number of studies have contributed to the formation of this study's propositions and conceptual framework, but further elaboration and continued verification should help confirm, refute, and enhance their validity to result in robust theory-building for organizational socialization. In fact, existing studies have presented valuable yet partial understandings regarding the relationships between the components (i.e., between developmental network characteristics and developmental functions, between developmental functions and developmental consequences, and between developmental network characteristics and developmental consequences). Moreover, these studies are dispersed across many disciplines, building weakly on each other, and hesitant to engage in theorizing organizational socialization (Tuttle, 2002). Given that a simple addition of parts neither explains a sophisticated mechanism in its entirety nor substantiates the epistemology of a certain phenomenon, subsequent empirical research is encouraged to look into the whole picture of organizational socialization. In doing so, additional considerations might need to be given to confounding variables, such as academic background and the tenure of the protégé (Dobrow, Chandler, Murphy, \& Kram, 2011) as well as organizational size and industry (Singh, Ragins, \& Tharenou, 2009).

Another research opportunity stems from the technical limitations of previous research. For example, many studies have suffered from methodological problems with respect to organizational factors at play. Since organizational socialization occurs among individuals affiliated with a given organization, collected data is likely to take a hierarchical structure that includes both the individual and organizational levels. Nevertheless, many studies have adopted a uni-level data analysis approach at the individual level, overlooking the interdependence and structural nature of data nested in the organization. This underestimates the standard error, expands the test statistics, and increases the risk of Type 1 errors in hypothesis verifications (Raudenbush \& Bryk, 2002). Thus, empirical examinations with a multi-level analytical approach are needed to help resolve these issues and produce more accurate analysis (Ragins, 1997). In a similar vein, the effects of various network indicators should be examined simultaneously (e.g., density with the network size, diversity with tie strength) because each indicator is unique yet intertwined with others in the network and thus, research results might be distorted if they are examined separately.

\section{Conclusion}

Few studies have explored the mechanism through which developmental networks conduce to the learning and organizational adaptation of employees. In an attempt to better understand this mechanism, as well as to further the concept of mentoring to organizational culture built on developmental networks, the current study proposed an integrated framework that depicts how developmental network characteristics affect organizational socialization through the network's developmental functions. However, as any others, this study has limitations that call for further inquiries.

First, not much attention was paid to the cultural context in the propositions and framework, which calls for crosssectional verification and challenges from diverse cultural contexts, both empirically and conceptually. Each regional/national culture has its own code of interpersonal interactions, which may be different from or similar to others (Briscoe, Randall, \& Tarque, 2016; Hofstede, 2001). In other words, the conceptualization in the current study would not be generalizable yet before being supported sufficiently with cross-cultural proofs. For example, it would be worth examining whether the framework proposed here holds true in the authoritarian society (with high power distance and collectivistic attributes) and the meritocratic society (with low power distance and individualistic attributes) alike or otherwise.

In parallel, it also deserves scholarly attention if this study's findings remain consistent regardless of gender and generation. It is presumable that those factors bring about commonalities and differences in the way of forming a network and getting benefits from it. Further, social capital embedded in a human network (e.g., gender and generation compositions) would not be value neutral but embody power and politics (Lin, 1999), and a similar network structure might function differently depending on those involved. For example, male and female protégés might have a dissimilar image about the role model; female developers might be different from their counterpart in terms of type and quality of developmental support they offer; the use of technology for networking and its impact on network configurations might be distinctive between older and younger workers.

Last but not least, a further consideration should be given to advancing information and communication technologies (ICTs) that transform the way of human interactions. Not only formal networks prescribed by organizations, emergent ones can be created more and easier than ever through virtual activities such as emails, social network services, and online meetings (Littlejohn, Foss, \& Oetzel, 2017). Furthermore, considering a myriad of ties established online and voluminous data coming from virtual interactions, data analytics that look into the virtual developmental networks will be another area for scholarly explorations. Reflecting on the tremendous velocity that ICTs permeate work and human relations and enhancing analytical capabilities 
accordingly would be a requisite for the research community for continued contributions going forward.

In conclusion, although integrative and practically relevant, this study is not meant to be a final product but to invigorate further research for theorization of organizational socialization in the networked ecology of work.

\section{References}

Adler, P. S., \& Kwon, S.-W. (2002). Social capital: Prospects for a new concept. Academy of Management Review, 27(1), 17-40.

Allen, T. D., Day, R., \& Lentz, E. (2005). The role of interpersonal comfort in mentoring relationships. Journal of Career Development, 31(3), 155-169.

Allen, T. D., Eby, L. T., Chao, G. T., \& Bauer, T. N. (2017). Taking stock of two relational aspects of organizational life: Tracing the history and shaping the future of socialization and mentoring research. Journal of Applied Psychology, 102(3), 324-337.

Anderson, N., Potočnik, K., \& Zhou, J. (2014). Innovation and creativity in organizations: A state-of-thescience review, prospective commentary, and guiding framework. Journal of Management, 40(5), 1297-1333.

Baker, V. L., \& Lattuca, L. R. (2010). Developmental networks and learning: Toward an interdisciplinary perspective on identity development during doctoral study. Studies in Higher Education, 35(7), 807-827.

Bauer, T. N., Bodner, T., Erdogan, B., Truxillo, D. M., \& Tucker, J. S. (2007). Newcomer adjustment during organizational socialization: A meta-analytic review of antecedents, outcomes, and methods. Journal of Applied Psychology, 92(3), 707-721.

Blickle, G., Witzki, A. H., \& Schneider, P. B. (2009). Selfinitiated mentoring and career success: A predictive field study. Journal of Vocational Behavior, 74(1), 94-101.

Blustein, D. L., Schultheiss, D. E. P., \& Flum, H. (2004). Toward a relational perspective of the psychology of careers and working: A social constructionist analysis. Journal of Vocational Behavior, 64(3), 423440.

Briscoe, D., Randall, S., \& Tarque, I. (2016). International Human Resource Management: Policies and Practices for Multinational Enterprises. New York, NY: Routledge.

Burke, R. J., \& McKeen, C. A. (1997). Benefits of mentoring relationships among managerial and professional women: A cautionary tale. Journal of Vocational Behavior, 51(1), 43-57.
Burlew, L. D. (1991). Multiple mentor model: A conceptual framework. Journal of Career Development, 17(3), 213-221.

Burt, R. S. (2005). Brokerage and Closure: An Introduction to Social Capital. New York, NY: Oxford University Press.

Callahan, J. L. (2010). Constructing a manuscript: Distinguishing integrative literature reviews and conceptual and theory articles. Human Resource Development Review, 9(3), 300-304.

Caplan, J. (2013). Strategic Talent Development: Develop and Engage all your People for Business Success. Philadelphia, PA: Kogan Page.

Chandler, D. E., \& Kram, K. E. (2005). Applying an adult development perspective to developmental networks. Career Development International, 10(6/7), 548-566.

Chang, J., \& Chang, W. (2009). The effects of mentoring networks and organizational characteristics on mentoring functions in the early careers. Journal of Vocational Education and Training, 12(3), 1-25.

Chao, G. T., O'Leary-Kelly, A. M., Wolf, S., Klein, H. J., \& Gardner, P. D. (1994). Organizational socialization: Its content and consequences. Journal of Applied Psychology, 79, 730-743.

Chermack, T. J., \& Passmore, D. L. (2005). Using journals and Databases in Research. In R. A. Swanson \& E. F. Holton (Eds.), Research in Organizations: Foundations and Methods of Inquiry (pp. 401-418). San Francisco, CA: Berrett-Koehler.

Coleman, J. S. (1987). Families and schools. Educational Researcher, 16, 32-38.

Cotton, R. D., Shen, Y., \& Livne-Tarandach, R. (2011). On becoming extraordinary: The content and structure of the developmental networks of major league baseball hall of famers. Academy of Management Journal, 54(1), 15-46.

Crossan, M. M., Lane, H. W., \& White, R. E. (1999). An organizational learning framework: From intuition to institution. Academy of Management Review, 24(3), 522-537.

Dobrow, S. R., Chandler, D. E., Murphy, W. M., \& Kram, K. E. (2011). A review of developmental networks: Incorporating a mutuality perspective. Journal of Management, 38(1), 210-242.

Dobrow, S. R., \& Higgins, M. C. (2005). Developmental networks and professional identity: A longitudinal study. Career Development International, 10(6/7), 567-583

Dougherty, T. W., Ha Cheung, Y., \& Florea, L. (2008). The role of personality in employee developmental networks. Journal of Managerial Psychology, 23(6), 
653-669

Fagenson-Eland, E. A., Marks, M. A., \& Amendola, K. L. (1997). Perceptions of mentoring relationships. Journal of Vocational Behavior, 51(1), 29-42.

Frey, C. B., \& Osborne, M. A. (2017). The future of employment: How susceptible are jobs to computerization?. Technological Forecasting and Social Change, 114, 254-280.

Gallo, A. (2011). Demystifying mentoring. Harvard Business Review. Retrieved June 20, 2018 from https://hbr.org/2011/02/demystifying-mentoring

Granovetter, M. S. (1973). The strength of weak ties. American Journal of Sociology, 78(6), 1360-1380.

Greenhaus, J. H., Callanan, G. A., \& Godshalk, V. M. (2009). Career Management (4th ed.). Thousand Oaks, CA: Sage.

Higgins, M. C., Dobrow, S. R., \& Chandler, D. (2008). Never quite good enough: The paradox of sticky developmental relationships for elite university graduates. Journal of Vocational Behavior, 72(2), 207-224

Higgins, M. C., \& Kram, K. E. (2001). Reconceptualizing mentoring at work: A developmental network perspective. Academy of Management Review, 26(2), 264-288.

Hofstede, G. (2001). Culture's Consequences: International Differences in Work-Related Values. London, UK: Sage.

Janssen, O. (2005). The joint impact of perceived influence and supervisor supportiveness on employee innovative behaviour. Journal of Occupational and Organizational Psychology, 78(4), 573-579.

Kammeyer-Mueller, J. D., \& Judge, T. A. (2008). A quantitative review of mentoring research: Test of a model. Journal of Vocational Behavior, 72(3), 269283.

Kim, D., \& Chung, C. (2016). Qualitative simulation on the dynamics between social capital and business performance in strategic networks. Journal of Distribution Science, 14(9), 31-45.

Kim, M.-J., Oh, H., \& Kim, M.-S. (2006). The effects of mentoring network characteristics on mentoring functions for protégés in an organization. The Korean Journal of Industrial and Organizational Psychology, 19(2), 229-258.

Korte, R., \& Lin, S. (2013). Getting on board: Organizational socialization and the contribution of social capital. Human Relations, 66(3), 407-428.

Kram, K. E. (1985). Mentoring at Work: Developmental Relationships in Organizational Life. Glenview, IL: Scott Foresman.

Lankau, M. J., \& Scandura, T. A. (2002). An investigation of personal learning in mentoring relationships: Content, antecedents, and consequences. Academy of Management Journal, 45(4), 779-790.

Lave, J., \& Wenger, E. (1991). Situated Learning: Legitimate Peripheral Participation. New York, NY: Cambridge University Press.

Lee, B. C. (2017). Social network effects on travel agency employees' occupational outcomes: Innovation behavior as a mediator. Journal of Distribution Science, 15(6), 13-24.

Lee, S., Lim, W., \& Suh, E. (2014). Youth startup firms: A case study on the survival strategy for creating business performance. Journal of Distribution Science, 12(6), 81-88.

Lin, N. (1999). Social networks and status attainment. Annual Review of Sociology, 25(1), 467-487.

Litano, M. L., \& Major, D. A. (2016). Facilitating a whole-life approach to career development: The role of organizational leadership. Journal of Career Development, 43(1), 52-65.

Littlejohn, S. W., Foss, K, A., \& Oetzel, J. G. (2017). Theories of Human Communication (11th ed.). Long Grove, IL: Waveland Press.

Lombardo, M., \& Eichinger, R. (2000). The Career Architect Development Planner (3rd ed.). Minneapolis, MN: Lominger Limited.

McElroy, J. C., \& Weng, Q. (2016). The connections between careers and organizations in the new career era: Questions answered, questions raised. Journal of Career Development, 43(1), 3-10.

Marsden, P. V. (1990). Network data and measurement. Annual Review of Sociology, 16, 435-463.

Marsick, V. J., \& Watkins, K. E. (2001). Informal and incidental learning. New Directions for Adult and Continuing Education, 89, 25-34.

Morrison, E. W. (2002). Newcomers' relationships: The role of social network ties during socialization. Academy of Management Journal, 45(6), 1149-1160.

Oh, H., Chung, M.-H., \& Labianca, G. (2004). Group social capital and group effectiveness: The role of informal socializing ties. Academy of Management Journal, 47(6), 860-875.

Parker, P., Cotton, R. D., Yates, M. S., Baxter, J., \& Arend, S. (2017). Developmental network structure and support: Gendered consequences for work-family strain and work-parenting strain in the Australian mining industry. The International Journal of Human Resource Management, 28, 1-31.

Ragins, B. R. (1997). Diversified mentoring relationships in organizations: A power perspective. The Academy of Management Review, 22(2), 482-521.

Raudenbush, S. W., \& Bryk, A. S. (2002). Hierarchical 
Linear Models: Applications and Data Analysis Methods (2nd ed.). Newbury Park, CA: Sage Publications.

Reagans, R., \& McEvily, B. (2003). Network structure and knowledge transfer: The effects of cohesion and range. Administrative Science Quarterly, 48(2), 240267.

Saks, A. M., Uggerslev, K. L., \& Fassina, N. E. (2007). Socialization tactics and newcomer adjustment: A meta-analytic review and test of a model. Journal of Vocational Behavior, 70(3), 413-446.

Scandura, T. A. (1992). Mentorship and career mobility: An empirical investigation. Journal of Organizational Behavior, 13(2), 169-174.

Scandura, T. A., \& Viator, R. E. (1994). Mentoring in public accounting firms: An analysis of mentor-protégé relationships, mentorship functions, and protégé turnover intentions. Accounting, Organizations and Society, 19(8), 717-734.

Schein, E. H. (1968). Organizational socialization and the profession of management. Industrial Management Review, 9(winter), 1-16.

Schwab, K. (2017). The Fourth Industrial Revolution. New York, NY: Crown Business.

Seibert, S. E., Kraimer, M. L., \& Liden, R. C. (2001). A social capital theory of career success. Academy of Management Journal, 44(2), 219-237.

Singh, R., Ragins, B. R., \& Tharenou, P. (2009). Who gets a mentor? A longitudinal assessment of the rising star hypothesis. Journal of Vocational Behavior, 74(1), 11-17.

Torraco, R. J. (2016). Writing integrative literature reviews: Using the past and present to explore the future. Human Resource Development Review, 15(4), 404428.

Tuttle, M. (2002). A review and critique of Van Maanen and Schein's "Toward a theory of organizational socialization" and implications for human resource development. Human Resource Development Review, 1(1), 66-90.

Uzzi, B. (1999). Embeddedness in the making of financial capital: How social relations and networks benefit firms seeking financing. American Sociological Review, 64(4), 481-505.

Van Maanen, J., \& Schein, E. H. (1979). Toward a Theory of Organizational Socialization. In B. M. Staw (Ed.), Research in Organizational Behavior (pp. 209-264). Greenwich, CT: JAI.

Wu, P.-C., Foo, M.-D., \& Turban, D. B. (2008). The role of personality in relationship closeness, developer assistance, and career success. Journal of Vocational Behavior, 73(3), 440-448.

Yang, C. C., Hu, C., Baranik, L. E., \& Lin, C. Y. (2013). Can protégés be successfully socialized without socialized mentors? A close look at mentorship formality. Journal of Career Development, 40(5), 408-423. 